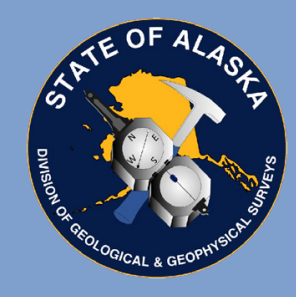

Coastal erosion and flooding damage and destroy infrastructure; threaten livelihoods, security, and life safety; and increase financial

\section{The DGGS Coastal Hazards}

Program works to map, monitor, and model flooding and erosion for Alaska's coastal communities

\section{7\% of all Alaska Native communities experience flooding and/or erosion} burdens on state and local economies.

The DGGS Coastal Hazards
Program works to map, monitor,
and model flooding and erosion for
Alaska's coastal communities

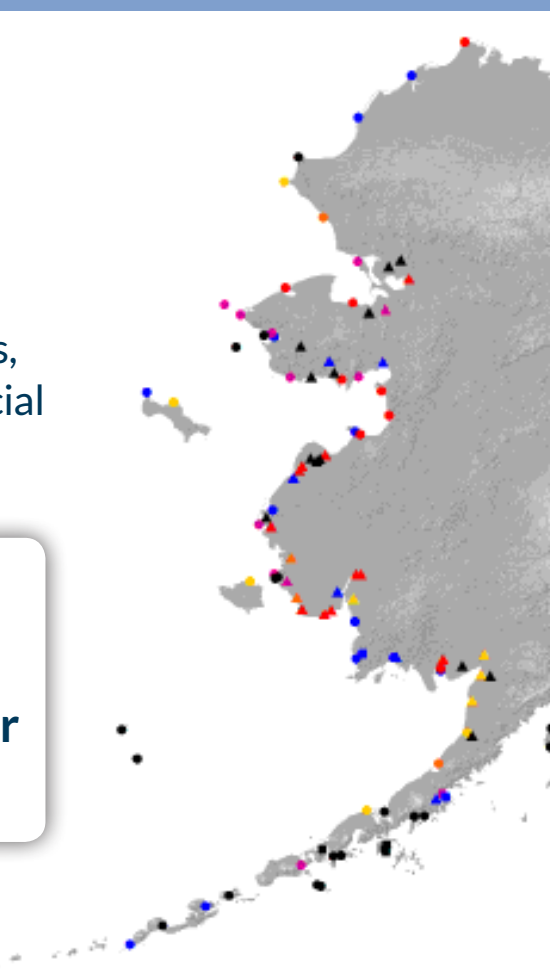

Erosion and flooding
are caused by:
Permafrost thaw
Coastal storms
occurring in an
ice-free ocean
Relative sea level rise
Changes to ocean
conditions

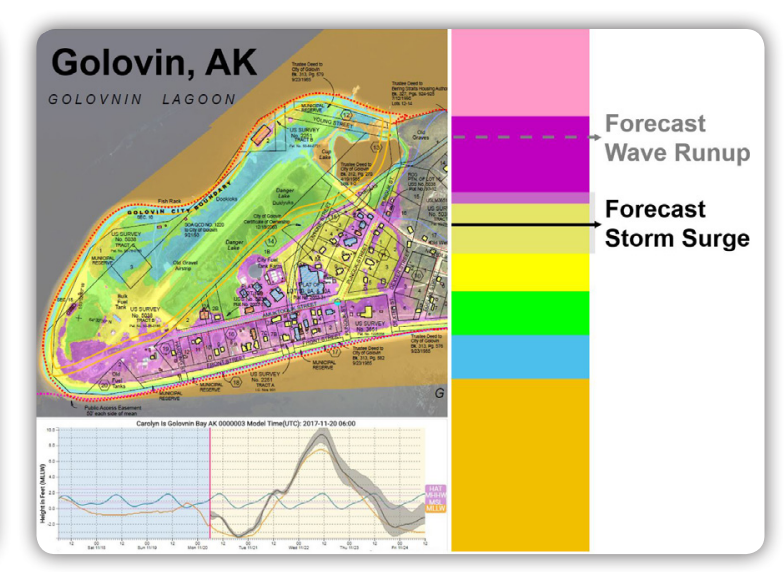

\section{Real-time Forecasting}

Coastal flooding forecasts are currently only available at a regional level and only take into account storm surge. Local forecasts are needed at individual communities to effectively respond to and avoid impacts to people and infrastructure. Storm forecasts must also include wave runup to predict total flooding.

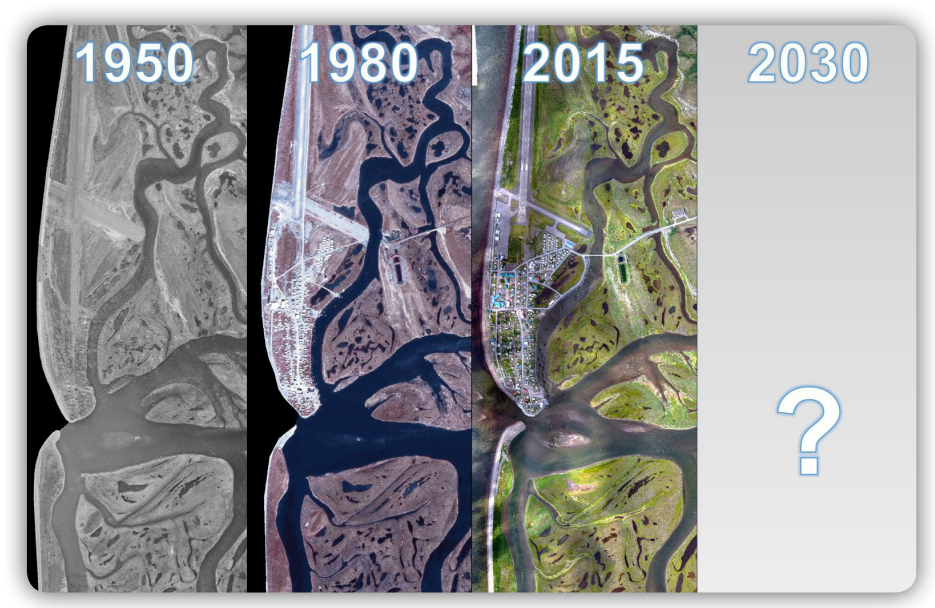

\section{Long-term Predictions}

If we want to plan for where the coast will be or how high we expect floods to reach, long-term models of flooding and erosion are necessary. This information feeds into climate change adaptation planning, community infrastructure placement, and engineering projects in the nearshore.

Above: On-the-fly updates of potential flood impact during storms Left: Orthorectified aerial photographs used to determine past shoreline positions 


\section{BASELINE DATA}

Huge strides have been made to improve baseline coastal data related to flooding and erosion using new technology and collaborative approaches. Large gaps in baseline data, however, still exist. Continuous monitoring efforts, both at the community level and through statewide initiatives, are required to provide accurate data and up-to-date assessments.

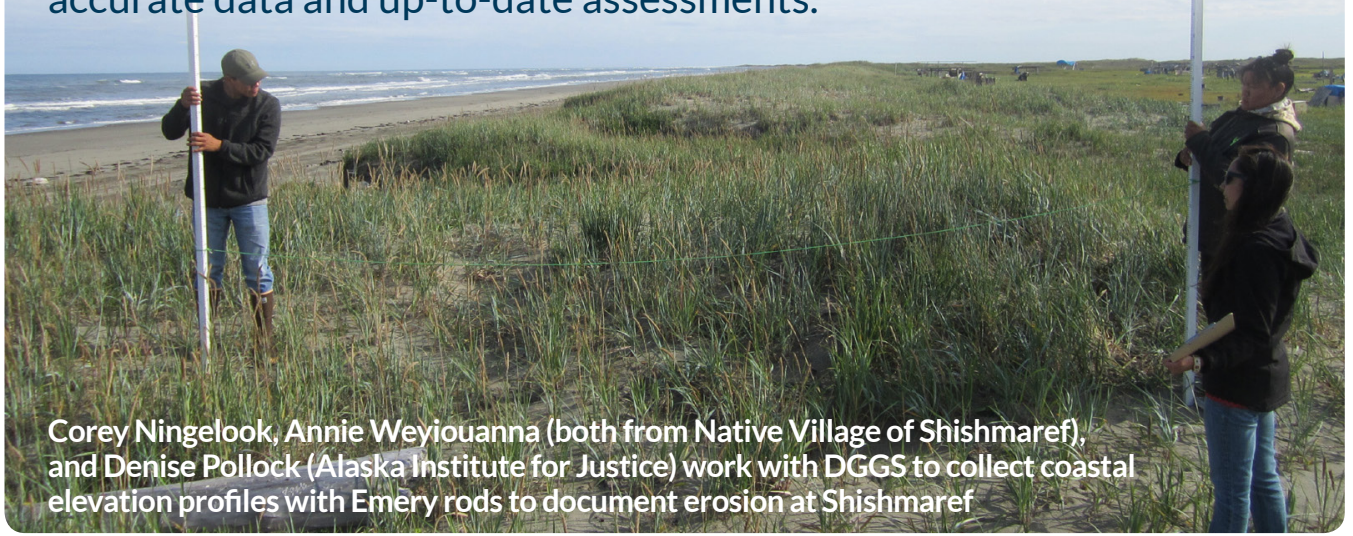

\section{Baseline Data Needs}

These are some of the types of data that are required to provide accurate assessments of coastal data in Alaska

Orthoimagery Topography Bathymetry Water levels Waves

Continually operating reference systems

Sea ice thickness and extent

\section{Predicting flood impacts requires} combining multiple baseline datasets to convert modeled storm water levels to local elevations. DGGS provides these products where adequate data is available.

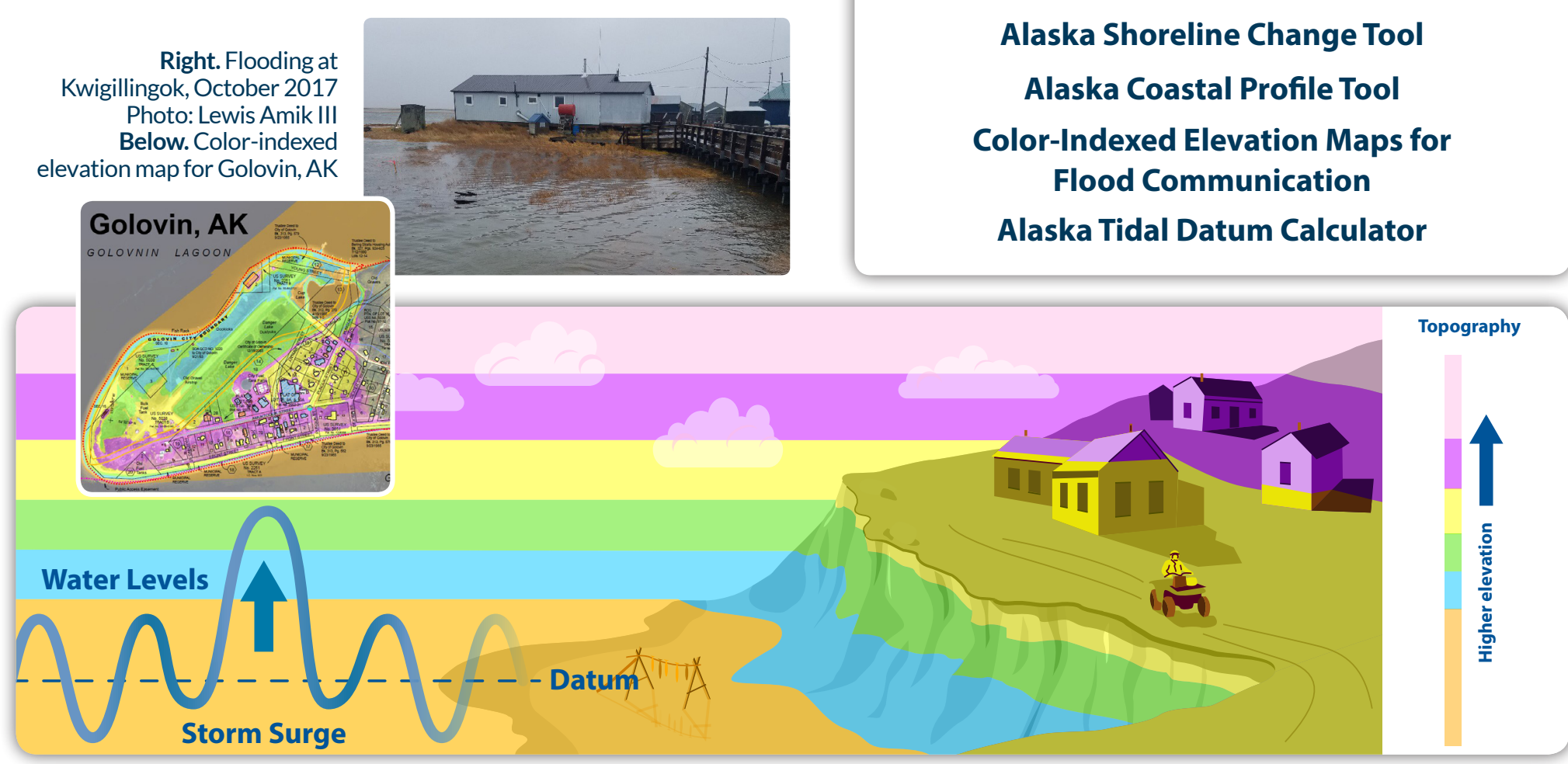

The figure above illustrates how each color corresponds to elevation on the color-indexed elevation map (above left).

\section{Online Tools for Coastal Hazards}

DGGS has several online tools that provide information about coastal hazards available at $\underline{\text { dggs.alaska.gov }}$

Alaska Shoreline Change Tool

Alaska Coastal Profile Tool Flood Communication

Alaska Tidal Datum Calculator 